\title{
Water-associated attributes in the contemporary dentin bonding milieu
}

\author{
Cesar R. Pucci ${ }^{\mathrm{a}, 1}$, Li-Sha Gu ${ }^{\mathrm{b}, 1}$, Hong-yun Zhang ${ }^{\mathrm{c}, 1}$, Qun Song' ${ }^{\mathrm{c}}$, Veronica Wang Xia ${ }^{\mathrm{d}}$, \\ Linsey B. Davis ${ }^{\mathrm{d}}$, Danilo de Souza Andrade ${ }^{\mathrm{a}}$, Annalisa Mazzoni ${ }^{\mathrm{e}}$, Lorenzo Breschi ${ }^{\mathrm{e}}$, \\ David H. Pashley ${ }^{\mathrm{d}}$, Franklin R. Tay ${ }^{\mathrm{c}, \mathrm{d}, *}$, Li-Na Niu ${ }^{\mathrm{c}, \mathrm{d}, \mathrm{f}, * * *}$
}

a Department of Restorative Dentistry, Institute of Science and Technology, São Paulo State University UNESP São Jose dos Campos, São Paulo, Brazil

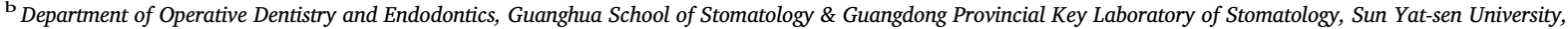
Guangzhou, China

${ }^{\mathrm{c}}$ State Key Laboratory of Military Stomatology \& National Clinical Research Center for Oral Diseases \& Shaanxi Key Laboratory of Stomatology, School of Stomatology, The Fourth Military Medical University, Xi'an, China

d Department of Endodontics, The Dental College of Georgia, Augusta University, Augusta, GA, USA

e Department of Biomedical and Neuromotor Sciences, DIBINEM, University of Bologna - Alma Mater Studiorum, Bologna, Italy

${ }^{\mathrm{f}}$ The Third Affiliated Hospital of Xinxiang Medical University, Xinxiang, Hena, China

\section{A R T I C L E I N F O}

\section{Keywords:}

Degradation

Permeability

Universal adhesives

Water sorption

Zymography

\begin{abstract}
A B S T R A C T
Objectives: The water-associated attributes of resin-dentin interfaces created by contemporary adhesives are important determinants of bond integrity and stability. In the present work, these attributes were estimated from the perspectives of causality, to examine the behavior of the first and most-recently launched versions of universal adhesives when applied in either the etch-and-rinse mode or the self-etch mode.

Methods: The immediate cause of interfacial permeability and the time-dependent cause of water sorption were investigated in conjunction with the intermediate effect of interface degradation and the more long-term effect of loss of mechanical strength, before and after thermomechanical cycling. The results were compared with control etch-and-rinse and self-etch adhesives.

Results: Although the introduction of this new class of universal adhesives has brought forth significant changes to the dental adhesion arena, including more application options, reduced bonding armamentarium and increased user friendliness, the water-associated attributes that are critical for making resin-dentin bonds more durable to environmental challenges and less susceptible to degradation have remained unchanged at large, when compared with benchmarks established by former classes of adhesives.

Conclusion: It appears that the current trend of adhesive development has brought forth significant changes but lacks the vigor that demarcates progress and technological sublimity.

Clinical significance: The advent of the user friendly universal adhesives has brought forth significant changes to the dental adhesion arena. However, the elements that are critical for making resin-dentin bonds more durable to environmental challenges and less susceptible to degradation have remained unchanged at large.
\end{abstract}

\section{Introduction}

The call for bonding synthetic materials to tooth structures has saturated the fabrics of contemporary restorative dentistry. Indeed, the boundary between the art of dental esthetic illusion and the practice of dental adhesion is becoming increasingly indiscriminate. As such, there is an ongoing trend among manufacturers to simplify single-bottle dentin bonding technology to satisfy clinicians' demand for adhesive procedures that are faster, less technique-sensitive and more user- friendly [1]. Recently introduced single-bottle adhesives also provide clinicians with the option of selecting the most optimal bonding mode, dictated by different clinical scenarios, for bonding different restorative materials to tooth structures. This clan of multi-mode universal adhesives is designed to bond to tooth structures via the etch-and-rinse mode, the self-etch mode or the selective-etch mode using the same bottle of adhesive solution [2]. Some manufacturers also incorporate 10-methacryloyloxydecyl dihydrogen phosphate (10-MDP) into their adhesives as a self-etching resin monomer [3] and as a primer for

\footnotetext{
* Corresponding author at: The Dental College of Georgia, Augusta University, Augusta, Georgia, USA

*** Corresponding author at: School of Stomatology, The Fourth Military Medical University, Xi'an, China.

E-mail addresses: ftay@augusta.edu (F.R. Tay), niulina831013@126.com (L.-N. Niu).

${ }^{1}$ These authors contributed equally to this work.
} 


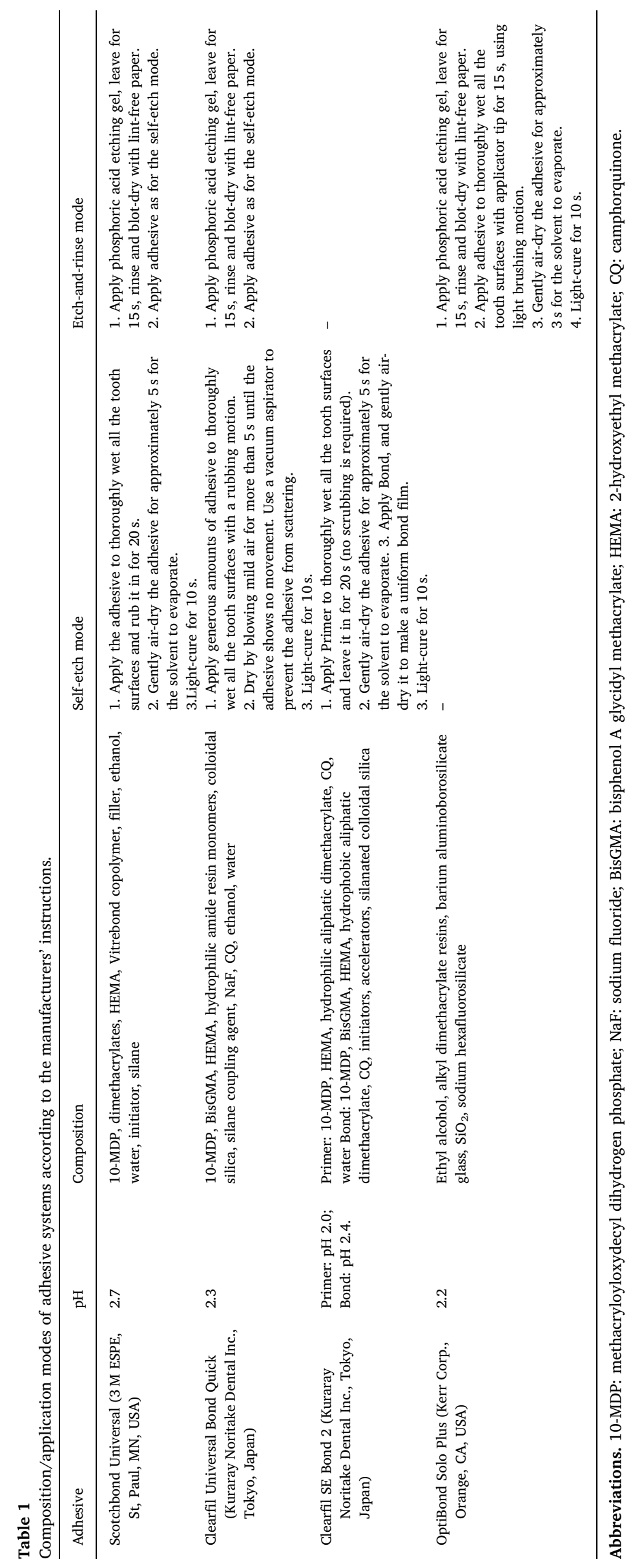


bonding zirconia-base ceramics [4].

A recent systematic review of universal adhesives surmised that acid-etching does not adversely affect the dentin bond strength of these adhesives [5]. However, the $\mathrm{pH}$ values of the adhesive agents and the smear layer thickness of bonding substrates significantly affect the ability of using these adhesives in the self-etch mode to dissolve the smear layer and partially demineralize the underlying intact dentin [6]. Residual water from the dentin surface and/or the adhesive solvent may compromise the performance of universal adhesives $[7,8]$. The technique of universal adhesive application is paramount for predictable outcomes associated with these adhesives $[9,10]$.

Introduction of the universal bonding concept, while appealing to clinicians, should not compromise adhesive bonding effectiveness and the durability of resin-dentin bonds [11]. Ideally, establishing a stable and durable resin-dentin interface with excellent sustainability should be the fervor for the creation of the next generation of dentin adhesives, which may be interpreted as "low-maintenance" in consumer culture's jargon [12]. Scotchbond Universal (3 M ESPE, St. Paul, MN, USA) was the first 10-MDP containing universal adhesive introduced into the market. Clearfil Universal Bond Quick (Kuraray Noritake Dental Inc., Tokyo, Japan) represents the most recently-launched 10-MDP containing universal adhesive.

In the present study, the notion that the water-associated attributes that adversely affect dentin bonding [1,13-16], identified in previous generation of adhesives, have been resolved with the advent of universal adhesives was challenged by examining the ultrastructure and permeability characteristics of resin-dentin interfaces bonded in the etch-and-rinse mode and the self-etch mode. The potential degradability of adhesive interfaces by endogenous enzymes present in mineralized dentin, and the adhesive bond strengths to dentin were examined before and after thermomechanical cycling. The water sorption characteristics of the polymerized adhesive resins were also investigated. Although many universal adhesives are commercially available, it is impractical to examine them all in a single piece of work. Hence the water-associated attributes of the first and the most recentlylaunched universal adhesives were examined and compared with a commercially available etch-and-rinse adhesive (OptiBond Solo Plus, Kerr Corporation, Orange, CA, USA) and a commercially available selfetch adhesive (Clearfil SE Bond 2, Kuraray Noritake Dental Inc., Tokyo, Japan). The null hypotheses tested were: 1) adhesive etching mode has no consequence on the intrinsic water permeability of the resin-dentin interfaces; 2) thermomechanical cycling has no effect on the gelatinolytic activity of resin-dentin interfaces created by either the etch-andrinse or the self-etch technique; 3 ) there is no difference in the microtensile bond strength of the four adhesives bonded to dentin before and after thermomechanical cycling; and 4) there is no difference among the four adhesive resin blends on water sorption.

\section{Materials and methods}

\subsection{Crown segments}

Two hundred and twenty-two extracted non-carious human third molars were collected based on a protocol approved by the Human Assurance Committee of the Augusta University, with informed consent obtained from the donating subjects with respect to the use of human tissues. The extracted teeth are stored in $0.9 \%(\mathrm{w} / \mathrm{v}) \mathrm{NaCl}$ containing $0.02 \%$ sodium azide at $4{ }^{\circ} \mathrm{C}$ for no longer than one month. The roots of the teeth were removed perpendicular to the longitudinal axis of the tooth, at $3.5 \mathrm{~mm}$ below the cement-enamel junction (CEJ), using a water-cooled low-speed diamond saw (Isomet, Buehler Ltd, Lake Bluff, IL, USA). For each tooth, a second parallel cut was used to remove the occlusal enamel and superficial dentin, creating a flat bonding surface consisting of mid-coronal dentin. A standard smear layer was manually created by wet-sanding the occlusal surfaces of crown segments with 320-grit silicon carbide paper under water irrigation for $1 \mathrm{~min}$.

\subsection{Bonding procedures}

The teeth were randomly assigned to six groups of twenty-nine teeth each according to the adhesive systems and bonding techniques. The compositions of the four adhesives are summarized in Table 1 . The two universal adhesives, Scotchbond Universal (SUB) and Clearfil Universal Bond Quick (CUBQ) were used in either the etch-and-rinse mode for the self-etch mode. OptiBond Solo Plus (OSP) was used in the etch-andrinse mode only while Clearfil SE Bond 2 (CSEB) was used in the selfetch mode only. For the etch-and-rinse bonding mode, a $35 \%$ phosphoric acid etchant (Select Hv Etch, Bisco, Inc., Schaumburg, IL, USA) was used for etching all teeth for $15 \mathrm{~s}$. A separate etchant was not used for bonding in the self-etch bonding mode. For both bonding modes, the adhesives were applied according to the manufacturer's instructions (Table 1). After light-curing of the adhesive, resin composite build-ups were constructed in four 1-mm thick increments using a hybrid resin composite (except for specimens designated for transmission electron microscopy, as reported in the corresponding section). Each increment was light-cured for $20 \mathrm{~s}$ using a light-emitting diode $(440-480 \mathrm{~nm}$ range) curing unit with an output intensity of $1200 \mathrm{~mW} / \mathrm{cm}^{2}$.

\subsection{Transmission electron microscopy}

Two teeth from each of the six groups were used for transmission electron microscopy (TEM) of the resin-dentin interface. After bonding with the respective adhesive, a 2-mm thick layer of microfilled resin composite was coupled to the polymerized adhesive to facilitate ultramicrotomy. Each bonded specimen was sectioned longitudinally through the center of the tooth to produce a 1-mm thick slab containing the resin-dentin interface. The specimens were fixed with Karnovsky's fixative ( $2.5 \mathrm{wt} \%$ glutaraldehyde and $2 \%$ paraformaldehyde in $0.1 \mathrm{~mol} /$ $\mathrm{L}$ cacodylate buffer; $\mathrm{pH}, 7.3$ ) for $8 \mathrm{~h}$, and post-fixed in $1 \%$ osmium tetroxide for $1 \mathrm{~h}$. The fixed specimens were dehydrated in an ascending ethanol series (50-100\%), immersed in propylene oxide as a transition medium, and embedded in pure epoxy resin. Ninety nanometer-thick sections were prepared using an ultramicrotome. The sections were examined unstained using a JEM-1230 TEM (JEOL, Tokyo, Japan) at $110 \mathrm{kV}$.

\subsection{Water permeability of bonded interfaces}

Five teeth in each adhesive group were designated for permeability examination of the bonded interfaces. A pair of calipers was used to control the remaining dentin thickness of each tooth to $2.5 \pm 0.1 \mathrm{~mm}$ from the deepest pulpal horn. A double fluorescence technique was employed to enable the adhesive and the water that permeated the resin-dentin interface to be identified simultaneously with confocal laser scanning microscopy (CLSM). Three drops of each adhesive system was mixed, respectively, with $1 \mu \mathrm{L}$ of a yellow fluorescent dye (Alexa Fluor $^{\mathrm{TM}}$ 532, excitation/emission: 532/553 nm; ThermoFisher Scientific, Waltham, MA, USA) to produce a homogeneous mixture. The fluorescent adhesives were kept in the dark until use. Each crown segment to be bonded was attached to a perforated Plexiglass block with cyanoacrylate blue. The assembly was connected via an 18-gauge stainless steel tube to a polyethylene tubing. The latter was attached to a column of a blue fluorescent dye-containing water (Alexa Fluor ${ }^{\mathrm{TM}} 405$, excitation/emission: $401 / 421 \mathrm{~nm}$; ThermoFisher Scientific) oriented $20 \mathrm{~cm}$ above the Plexiglass block to simulate the delivery of physiologic intrapulpal pressure (Fig. 2a). Intrapulpal pressure was applied to the prepared dentin surface during the adhesive procedures and resin composite build-up. The set-up was left in the dark for $4 \mathrm{~h}$ after completion of the bonding and restorative procedures to enable water to continue permeate the resin-dentin interface.

After completion of the water permeation protocol, each bond crown segment was removed from the Plexiglass block and sectioned longitudinally through the center of the tooth to retrieve 1 -mm thick 
slab containing the water-perfused resin-dentin interface. Each slab was fixed to a glass slide with Loctite Super Glue (Henkel, Rocky Hill, CT) and serially polished with 600 - and 1200 -grit wet silicon carbide papers to obtain a $\sim 50 \mu \mathrm{m}$-thick section. Final polishing was achieved using 4000-grit wet silicon carbide paper (MicroCut S-P400; Buehler Ltd.) for 5 min to obtain a glossy surface for CLSM examination. Microscopy was performed by an independent observer who was unaware of the treatment applied to the crown segments. Examination was performed using a two-photon CLSM (LSM 710 NLO, Carl Zeiss, Oberkochen, Germany). Three $85 \mu \mathrm{m}$ thick optical section series were acquired per slab from different focal planes ( $\mathrm{N}=15$ images). One image was taken from the center of each slab, and the other two images were taken from each side where the remaining dentin thickness was the thinnest from the dentin surface. The images were stacked and processed with the ZEN 2010 software (Carl Zeiss). Blue fluorescence within and above the hybrid layer was quantified using Image $\mathrm{J}$ (National Institutes of Health, Bethesda, MD) to represent the relative permeability of the respective resin-dentin interface.

\subsection{In-situ zymography}

Although pre-forms of dentin matrix-bound endogenous proteases are activated during demineralization of the collagen fibrils and adhesive application, degradation of the denuded collagen fibrils within hybrid layers requires specimen aging for 9-12 months before visible evidence of collagen degradation could be identified by TEM [17] because of the highly cross-linked nature of dentin collagen [18]. In-situ zymography is a laboratory technique that enables rapid localization of matrix metalloproteinases (MMP) activity in histological sections [19]. The technique utilizes gelatin conjugated to quenched fluorescein as the substrate for identifying the location and activities of activated endogenous enzymes within the resin-dentin interfaces [20]. Hence, insitu zymography may be used as an expedited, quantifiable method for comparing the relative degradation potential of resin-dentin interfaces, without relying on actual degradation of the resin-sparse, water-rich denuded collagen fibrils. In the present work, a double fluorescence technique was employed to enable the locations of the dentin adhesive and the activated endogenous enzymes to be identified simultaneously with CLSM (Fig. 3a). For the preparation of fluorescent adhesives, one grain of tetramethylrhodamine B isothiocyanate (excitation/emission: $540 / 625 \mathrm{~nm}$; MilliporeSigma, St. Louis, MO, USA) was dissolved in 3 drops of each adhesive.

Ten teeth in each adhesive group were designated for in-situ zymography of the resin-dentin interface. The dyed adhesives were used for dentin bonding, as previous described. The ten bonded teeth were divided into two subgroups. Five teeth were stored in deionized water at $37^{\circ} \mathrm{C}$ for $24 \mathrm{~h}$. The other five teeth were subjected to thermomechanical challenge, using 10,000 thermal cycles $\left(10^{\circ} \mathrm{C}\right.$ for one min, $25^{\circ} \mathrm{C}$ for one min and $55^{\circ} \mathrm{C}$ for one min) and 240,000 mechanical cycles, corresponding to one year of intraoral functioning [21]. Simulated aging was performed in a thermomechanical wear system (Model ER37000; Erios, São Paulo, SP, Brazil).

A $1-\mathrm{mm}$ thick slab containing the resin-dentin interface was retrieved from the center of each bonded crown segment. The slab was affixed to a glass slide and polished to $\sim 50 \mu \mathrm{m}$-thick, as described in the previous section. In-situ zymography was performed with the EnzChek $^{\mathrm{TM}}$ Gelatinase/Collagenase Assay Kit (E-12055, Molecular Probes, Eugene, OR, USA). Briefly, $50 \mu \mathrm{L}$ of the quenched fluoresceinconjugated gelatin mixture was placed on top of each slab and protected with a cover slip. Slides were light-protected and incubated in a $100 \%$ relative humidity chamber at $37^{\circ} \mathrm{C}$ for $48 \mathrm{~h}$. Hydrolysis of the quenched fluorescein-conjugated gelatin releases fluorescein (excitation/emission: 458/540 nm). Microscopy was performed by an independent observer who was unaware of the treatment applied to the crown segments. Green fluorescence was imaged together with the red fluorescence released by the adhesive using different channels of the two-photon CLSM. For each of the 5 slabs in each subgroup (with or without thermomechanical cycling), three image series were taken for gelatinolytic activity evaluation $(\mathrm{N}=15)$. One series was taken from the center of each slab, and the other two series were taken from each side where the remaining dentin thickness was the thinnest from the dentin surface. For each area, 20 optical sections ( $350 \mathrm{~nm}$ thick) were acquired from different focal planes. Fluorescence intensity emitted by degraded fluorescent peptides was quantified from the stacked image of each series using the Image $\mathrm{J}$ software. Gelatinolytic activity was expressed as the percentage of the resin-dentin interface that exhibited green fluorescence.

\subsection{Microtensile bond strength}

Twenty teeth in each adhesive group were designated for bond strength testing, using the non-trimmed version of the microtensile bond testing method [22]. After bonding with the undyed adhesives and restoration with hybrid resin composite, 10 teeth per group were stored in deionized water at $37^{\circ} \mathrm{C}$ for $24 \mathrm{~h}$ and 10 teeth were thermomechanically cycled in the manner described in the previous section. Each bonded crown segment were sectioned in the $\mathrm{x}$ and $\mathrm{y}$ directions across the resin-dentin interface to obtain beams with cross-sectional areas of approximately $0.9 \mathrm{~mm} \times 0.9 \mathrm{~mm}$. The four longest beams were obtained from the two central slabs of each bonded crown segment were used for bond strength testing. Each was secured with cyanoacrylate glue (Zapit; Dental Ventures of America, Corona, CA, USA) to a testing jig and stressed to failure under tension in a universal testing machine (Vitrodyne V1000; Liveco Inc., Burlington, VT, USA) at a cross-head speed of $1 \mathrm{~mm} / \mathrm{min}$. The tensile load at failure was recorded and divided by the measured cross-sectioned area of each beam to yield the tensile bond strength in megaPascals ( $\mathrm{MPa}$ ). The mean bond strength value derived from the 4 beams of each tooth was used to represent the microtensile bond strength of that particular tooth. Data analysis was subsequently performed using the tooth as the statistical unit $(\mathrm{N}=10$ teeth).

\subsection{Water sorption}

Six specimen disks $(5 \pm 0.1 \mathrm{~mm}$ diameter, $1 \pm 0.1 \mathrm{~mm}$ thick $)$ were fabricated for each adhesive group. The adhesives were dispensed into light-protected vials and placed in a vacuum chamber in the dark for $72 \mathrm{~h}$ to remove the adhesive solvent. The neat resin was dispensed into a Teflon split ring mold placed between two Mylar sheets. The solvent-free resin was first light-cured over the center of the disk for $40 \mathrm{~s}$, and then over eight peripheral overlapping sections for $20 \mathrm{~s}$ each. After storage in a desiccator with silica gel at $37^{\circ} \mathrm{C}$ for $24 \mathrm{~h}$, the specimens were weighed in an electronic analytical balance with a reproducibility of $0.01 \mathrm{mg}$ (Model XP 205PR; Mettler Toledo, Columbus, $\mathrm{OH}$, USA) until a constant mass $\left(\mathrm{M}_{1}\right)$ was obtained $(\mathrm{N}=6)$. The diameter and the thickness of the specimens were measured at four points using a pair of digital calipers for calculation of disk volume (V).

Each resin disk was stored separately in a Parafilm-sealed glass vial containing $20 \mathrm{~mL}$ of deionized water at room temperature for 24 days. During sorption, the specimens were weighted every $3 \mathrm{~h}$ during the first day, every $6 \mathrm{~h}$ during the second day, every $12 \mathrm{~h}$ during the third and fourth days and then daily thereafter. The disks were weighed until a constant mass was obtained $\left(\mathrm{M}_{2}\right)$ for the four adhesives at the end of the 24-day period. Percent mass gain or loss at equilibrium was calculated for each resin disk using the equation $\left(\mathrm{M}_{2}-\mathrm{M}_{1}\right) / \mathrm{V} * 100 \%$ [23].

\subsection{Statistical analyses}

Interval data generated from the experiments were examined for their normality (Shapiro-Wilk test) and equal variance assumptions (modified Levene test) prior to the adoption of parametric statistical methods. Statistical significance for all analyses was pre-set set at $\alpha=0.05$. 
Data for relative permeability of the resin-dentin interfaces were non-linearly transformed to satisfy the equal variance assumption prior to analysis with one-factor analysis of variance and post-hoc pairwise comparisons with the Holm-Šidák statistic. Data generated from in-situ zymography were analyzed with a two-factor analysis of variance design to examine the effects of "adhesive/application mode" and "thermomechanical cycling", and the interaction of those two factors on percent gelatinolytic activity. The Holm-Šidák statistic was employed for post-hoc pairwise comparisons. The original data sets generated from microtensile testing did not conform to the requirements for the use of parametric statistical methods. Hence, the data were nonlinearly transformed prior to analysis with two-factor analysis of variance to examine the effects of "adhesive/application mode" and "thermomechanical cycling", and the interaction of those two factors on dentin bond strength. The Holm-Šidák statistic was employed for post-hoc pairwise comparisons. Data of maximum water sorption in the four adhesive resin groups were analyzed with one-factor analysis of variance followed by Holm-Šidák pairwise comparisons. Because mass loss after water sorption was identified in two adhesive resin groups only, the maximum solubility data were analyzed with Student's $t$-test.

\section{Results}

Representative ultrastructural images of the resin-dentin interfaces produced by different adhesives in the designated etching modes are shown in Fig. 1. The thickness of hybrid layers generated by the etchand-rinse mode and self-etch mode were consistent among difference adhesives, and were $\sim 5 \mu \mathrm{m}$ and $\sim 0.5 \mu \mathrm{m}$ thick, respectively. Both extrafibrillar and intrafibrillar minerals were completely depleted within the resin-infiltrated collagen matrix when adhesives were applied to the phosphoric acid-etched dentin. For adhesives used in the self-etch mode, no gradient of mineral depletion could be identified from the partially-demineralized hybrid layers. At high magnification, mineral depletion appeared to be uniform within the entire thickness of the hybrid layers generated by the control self-etch adhesive or the universal adhesives employed in the self-etch mode. Electron-dense nanolayered structures were purportedly created, according to the "adhesion-decalcification concept", by self-assembly of the calcium salts of 10-MDP molecules following their ionic interaction with apatite [24]. Similar to a previous study [25], however, these structures could hardly be identified from the resin-dentin interfaces produced by the 10-MDP containing SUB, CUBQ and CSEB adhesives irrespective of whether the etch-and-rinse or the self-etch adhesive application mode was employed.

Representative CLSM images (separate channels; yellow for adhesive, blue for water permeability) of interfacial permeability within the interfaces created with adhesives applied in the etch-and-rinse mode or self-etch mode are shown in Fig. 2b. Ideally, the adhesive-filled hybrid layer and dentinal tubules should be able to prevent water movement through the resin-dentin interface, with no overlap between the two fluorescences (Fig. 2a). For the 3 adhesives used in the etchand-rinse mode, none was able to prevent some form of water permeation through the resin-infiltrated hybrid layer or the polymerized adhesive. For SUB and OSP applied in the etch-and-rinse mode, interfacial permeability was also manifested as water bubbles above the hybrid layer, or as a thin water film between the adhesive and the resin composite. Similar features could also be identified when SUB was used in the self-etch mode. Complete lack of interfacial permeability was only identified in 7 out of 10 specimens in dentin bonded with the CSEB self-etch adhesive.

Quantified interfacial permeability data are depicted in the bar chart in Fig. 2c. Two factor analysis of variance of the relative permeability results indicate that the factor "adhesive" did not significantly affect interfacial permeability $(\mathrm{p}=0.088)$. However, interfacial permeability was significantly more extensive when adhesives were used in the etch-and-rinse mode, compared with the self-etch mode $(p=0.01)$. One-factor analysis of variance showed that interfacial permeability was significantly influenced by the combined factor "adhesive/application mode" $(\mathrm{p}<0.001)$. Pairwise comparisons indicated that interfacial permeability was in the order (from the most extensive to the least extensive): OSP $=\mathrm{SUB}$ /etch-and-rinse $>$ CUBQ/ etch-and-rinse $=\mathrm{SUB} /$ self-etch $>$ CUBQ $/$ self-etch $>$ CSEB

( $\mathrm{p}<0.05)$.

Using a single-fluorescence in-situ zymography technique, proteolytic activities had previously been identified in hybrid layers created with etch-and-rinse and self-etch adhesives [26]. Representative dualfluorescence in-situ zymography performed on dentin bonded with the four adhesives in different etching modes are shown in Fig. 3b. The CLSM images were taken before or after thermomechanical cycling. In those merged-channel images, red fluorescence was identified in areas occupied by the rhodamine-incorporated adhesive. Stronger fluorescence was present in the adhesive layer and in resin tags within the dentinal tubules while weaker fluorescence was identified in the hybrid layers. Green fluorescence, which was indicative of the release of the heavily-quenched fluorescein by endogenous dentin gelatinases, could be identified in the hybrid layers and in the dentinal tubules. Intratubular gelatinolytic activities [20], which were thought to be derived from the proteins that regulate peritubular dentin formation [27], or by precipitation of dentinal fluid-derived matrix metalloproteinases during laboratory specimen processing [28], were not taken into account during quantitative evaluation of the gelatinolytic activities of the resin-dentin interfaces. Areas within hybrid layers that exhibited gelatinolytic activities (i.e. green fluorescence) before and after thermomechanical cycling are collectively represented in Fig. 3c. The percentages of hybrid layers exhibiting gelatinolytic activities were significantly affected by the combined factor "adhesive/application mode" $(\mathrm{p}<0.01)$ and the factor "thermomechanical cycling" $(\mathrm{p}<0.05)$. The interaction of these two factors was not statistically significant ( $p=0.106$ ). Prior to thermomechanical cycling, gelatinolytic activities of hybrid layers created by adhesives bonded using different application modes were in the order (from the highest to the lowest): SUB/selfetch $>$ OSP $=$ SUB/etch-and-rinse $>$ CUBQ/etch-and-rinse $=$ CUBQ/ self-etch $>$ CSEB $(\mathrm{p}<0.05)$. After thermomechanical cycling, gelatinolytic activities were in the order: SUB/self-etch $=$ SUB/etch-andrinse $=$ OSP > CUBQ/etch-and-rinse $=$ CUBQ/self-etch > CUBQ/ self-etch $=$ CSEB. For comparisons of different adhesive/application mode combinations, only SUB used in the etch-and-rinse mode exhibited significantly more gelatinolytic activities within the hybrid layers after thermomechanical cycling $(\mathrm{p}<0.05)$.

Resin-dentin microtensile bond strengths are summarized in Fig. 4a. Bond strengths were significantly affected by the combined factor "adhesive/application mode" ( $\mathrm{p}<0.05)$ and the factor "thermomechanical cycling" ( $\mathrm{p}<0.01$ ). The interaction of these two factors are not statistically significant $(\mathrm{p}=0.302$ ). Whereas there was no significant difference in bonding performance prior to thermomechanical cycling ( $p>0.05$ ), bond strengths of the six groups were significantly different after thermomechanical cycling $(\mathrm{p}<0.05)$. Pairwise comparisons indicated that the bond strengths were of the order (from the highest to the lowest): CSEB $=$ CUBQ/self-etch $=$ CUBQ/etch-andrinse $=$ SUB $/$ self-etch $=$ OSP $>$ OSP $=$ SUB $/$ etch-and-rinse

( $\mathrm{p}<0.05)$.

Polymerized, solvent-free resin disks created from SUB, CUBQ, OSP and CSEB demonstrated two mass alteration trends after immersion in deionized water for 24 days. Only mass gain was identified for CUBQ and CSEB resin disks while those prepared from SUB and OSP exhibited initial, rapid mass gain that was followed by substantial mass loss (Fig. 4b). For SEB and CUBQ, water sorption was characterized by rapid initial mass gain that gradually slowed down and reaching a plateau by the end of 14 days. For SUB and OSP, maximum water sorption was achieved as early as $48 \mathrm{~h}$. Water sorption was followed by leaching of resin components, with continuous mass loss that reached a plateau after 7 days. Maximum water sorption values for the four adhesive resin 


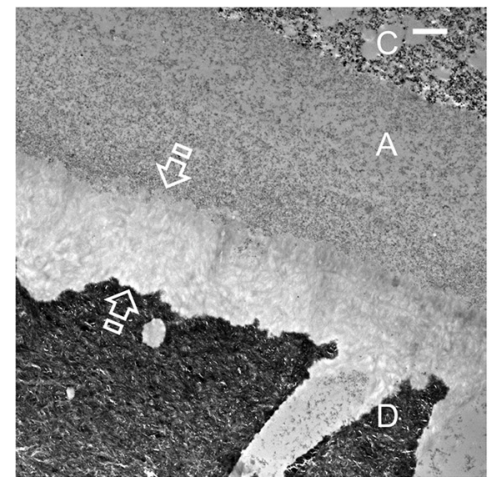

Scotchbond Universal

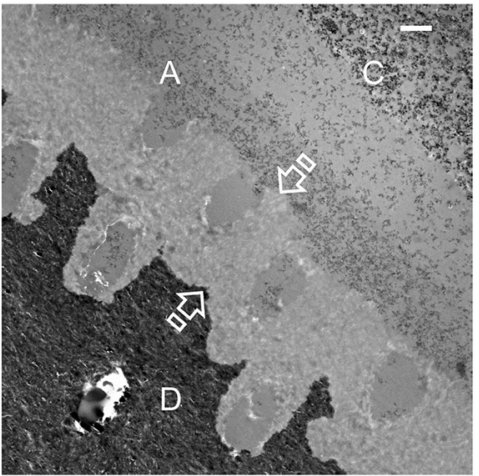

Clearfil Universal Bond Quick

Etch-and -rinse mode

Bar $=2 \mu \mathrm{m}$

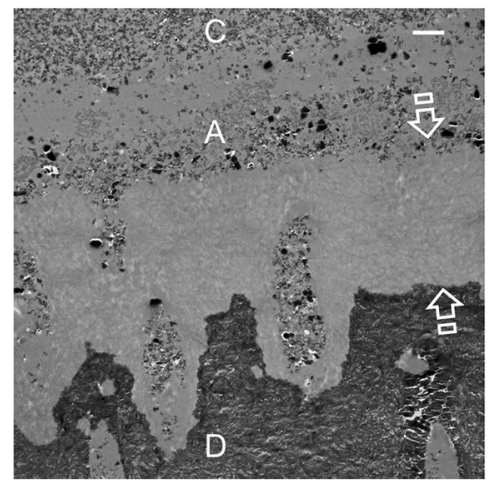

OptiBond Solo Plus (control 2-step etch-and-rinse adhesive)

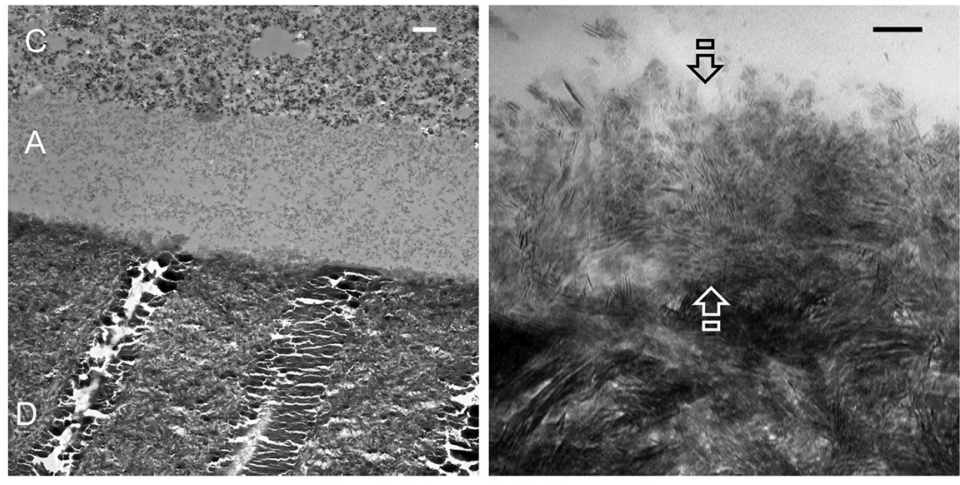

Scotchbond Universal

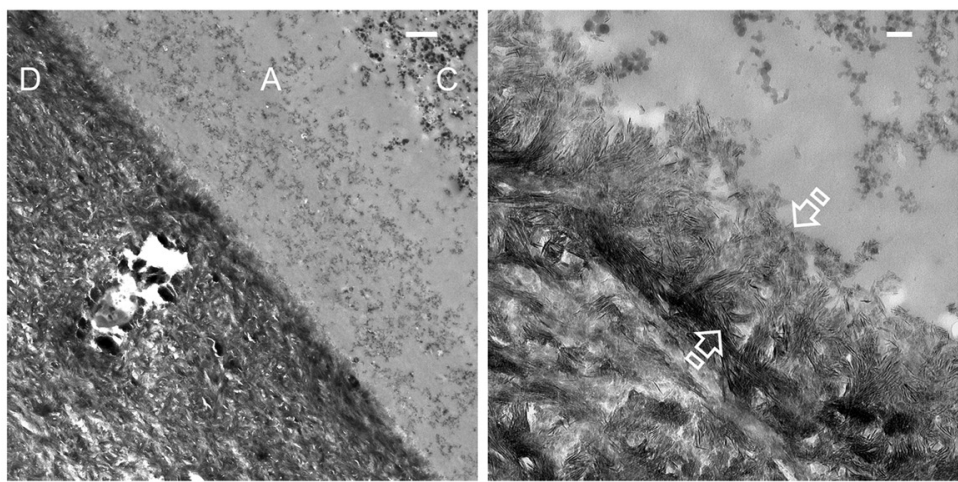

Clearfil Universal Bond Quick

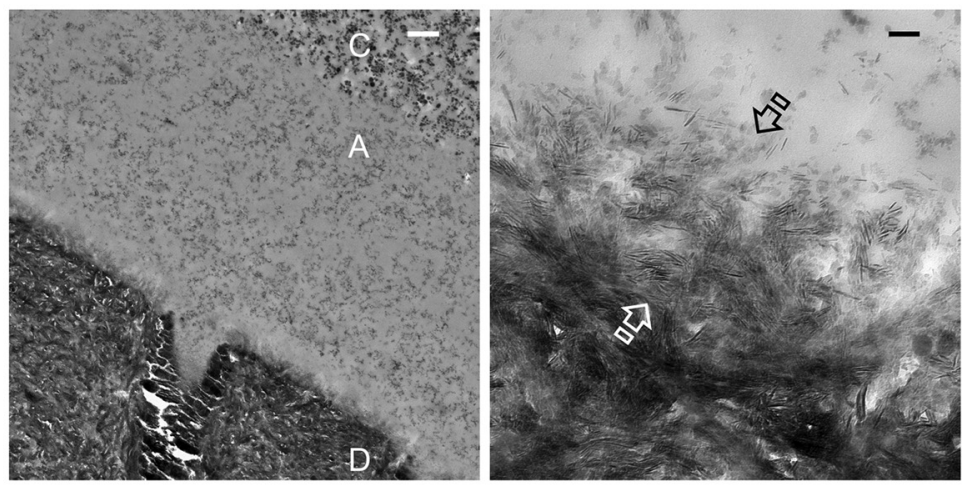

Clearfil SE Bond (control 2-step self-etch adhesive)

\section{Self-etch mode}

\section{$\mathrm{Bar}=100 \mathrm{~nm}$}

Fig. 1. Transmission electron microscopy of unstained, non-demineralized sections of resin-dentin interfaces created by the use of the two universal adhesives in the etch-and rinse mode or self-etch mode, the control two-step etch-and-rinse adhesive and the control two step self-etch adhesive. Abbreviations: C: resin composite; A: adhesive; D: intertubular dentin. For adhesives used in the etch-and-rinse mode, the hybrid layer is represented by the space between the opposing open arrows (left column). For adhesives used in the self-etch mode, the zone of partial demineralization is represented by the space between the opposing open arrows (right column). 

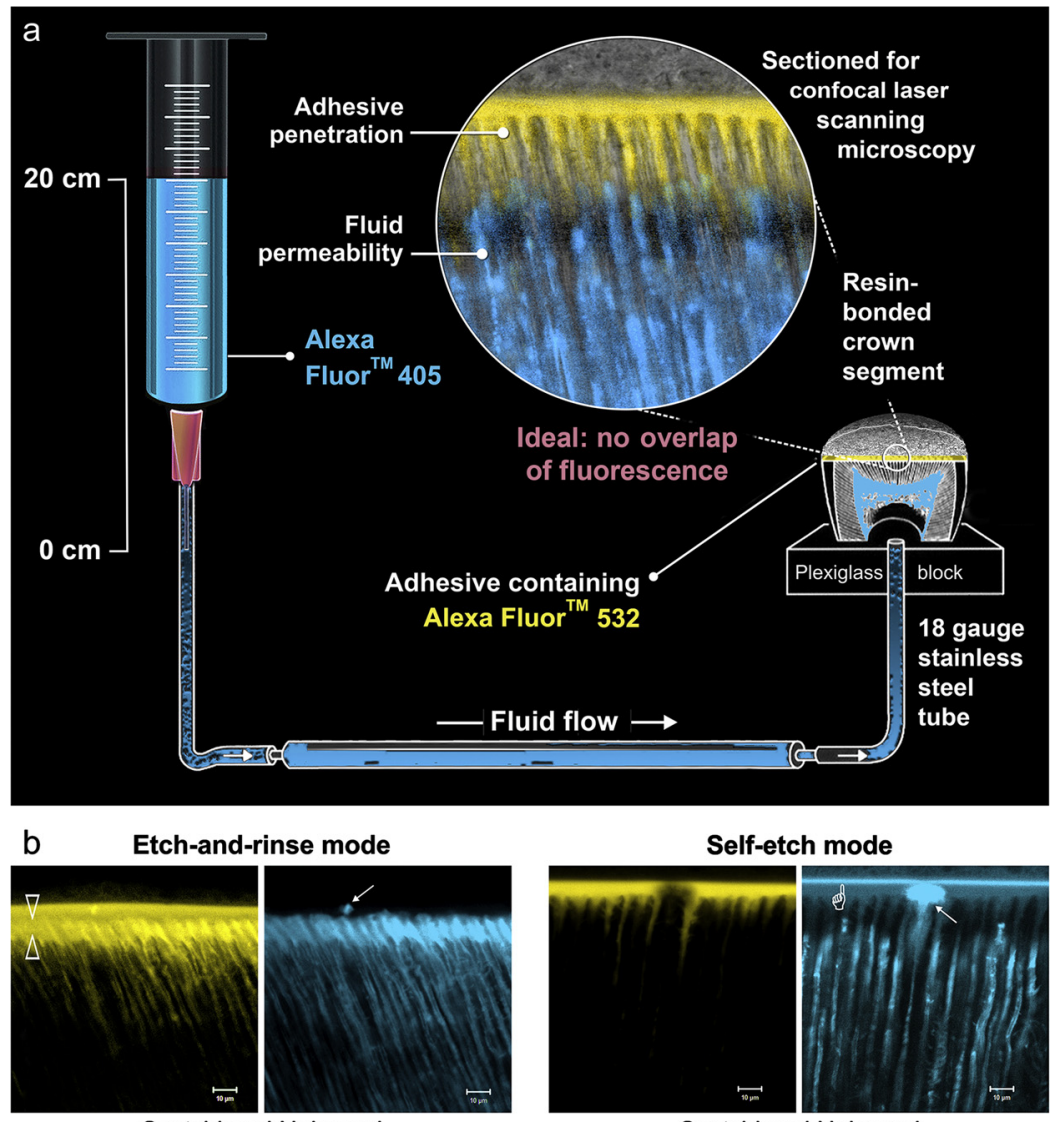

Scotchbond Universal

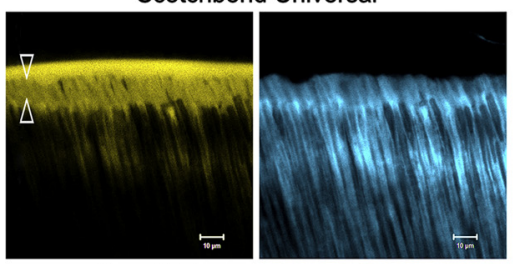

Clearfil Universal Bond Quick

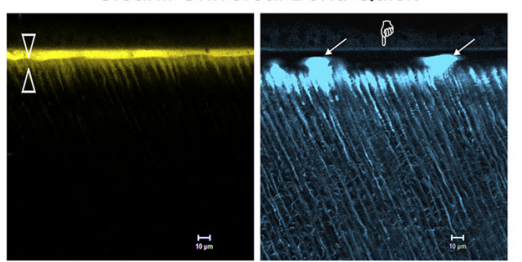

OptiBond Solo Plus

(control 2-step etch-and-rinse adhesive)

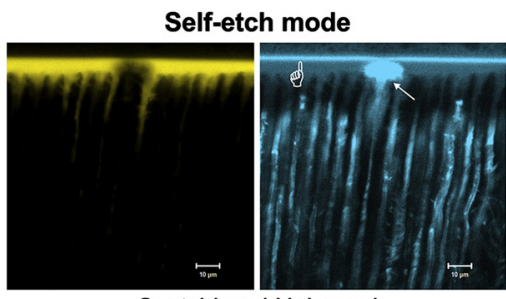

Scotchbond Universal

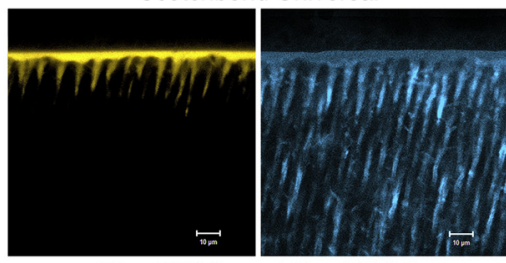

Clearfil Universal Bond Quick

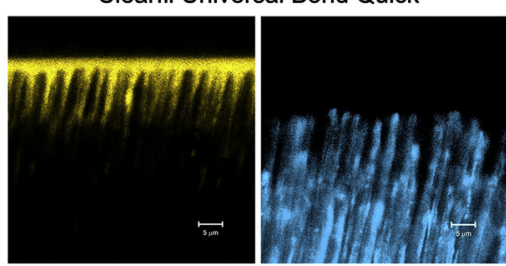

Clearfil SE Bond

(control 2-step self-etch adhesive)

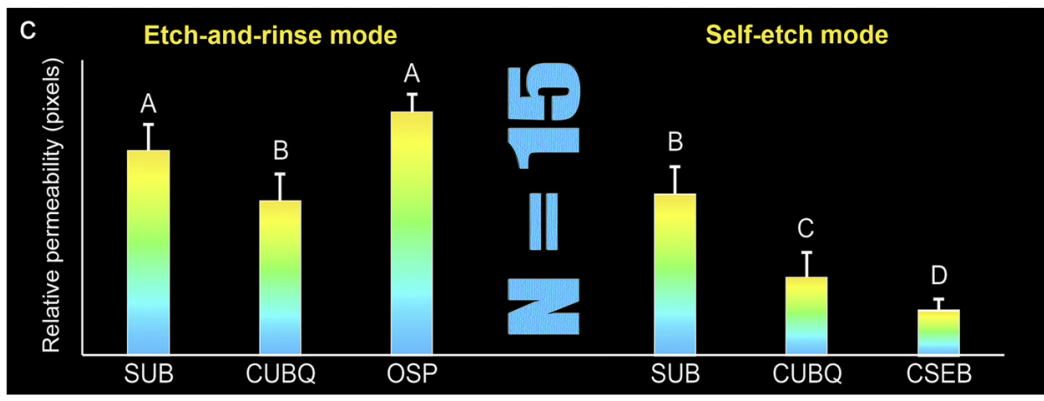

Fig. 2. Permeability characteristics of resin-dentin interfaces. a. Schematic of the experimental design. b. Representative CLSM images (separate channels; yellow fluorescence for adhesive, blue fluorescence for water permeability) of interfacial permeability within the interfaces created with adhesives applied in the etchand-rinse mode or self-etch mode. Bars $=10 \mu \mathrm{m}$. Yellow channel images (left column): hybrid layers created by adhesives in the etch-and-rinse mode are depicted by the spaces between two opposing open arrowheads. Blue channel images: water bubbles within the resin-dentin interfaces are indicated by arrows; water films between the adhesive and resin composite are indicated by pointers. c. Bar chart summarizing the relative interfacial permeability of resin-dentin interfaces created with adhesives applied in the etch-and-rinse mode or self-etch mode. Values are means and standard deviations. Columns labeled with the same upper case letters are not significantly different ( $p>0.05$ ). (For interpretation of the references to colour in this figure legend, the reader is referred to the web version of this article.) 
a

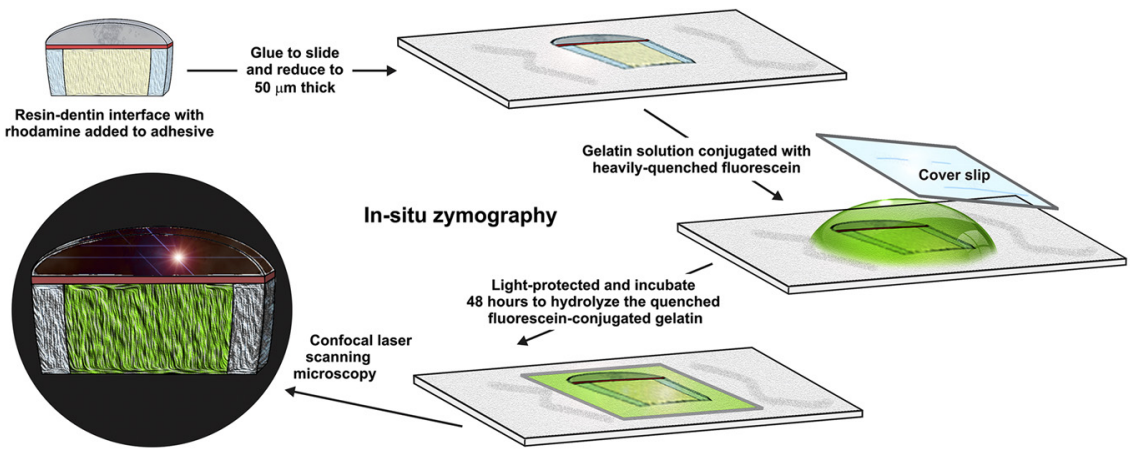

b Etch-and-rinse mode

Endogenous Gelatinolytic Activity

Before thermomechanical cycling After thermomechanical cycling
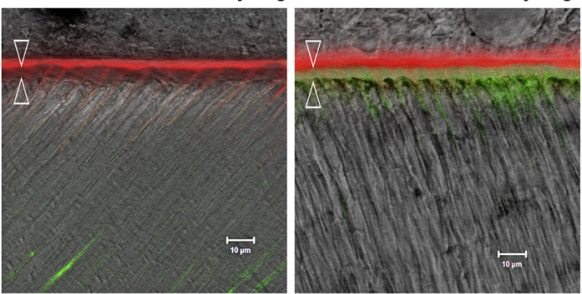

Scotchbond Universa
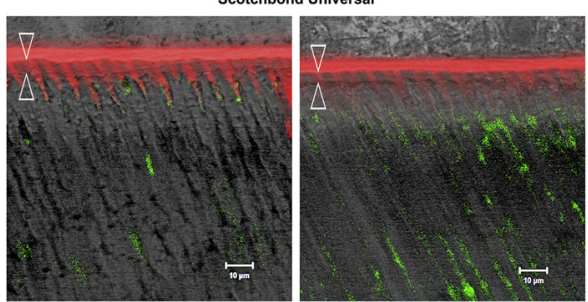

Clearfil Universal Bond Quick
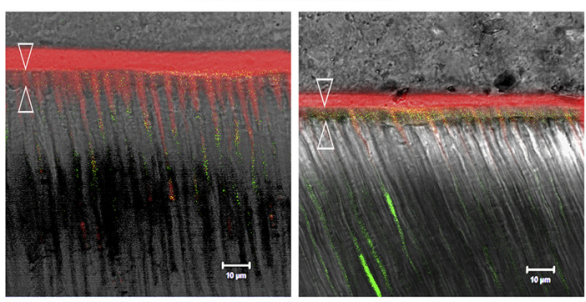

OptiBond Solo Plus (control 2-step etch-8-rinse adhesive)

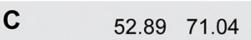

$\begin{array}{rr}52.89 & 71.04 \\ (10.27)(10.06)\end{array}$

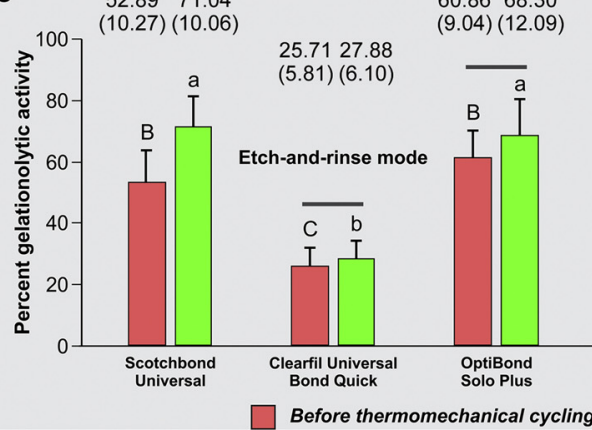

Before thermomechanical cycling After thermomechanical cycling

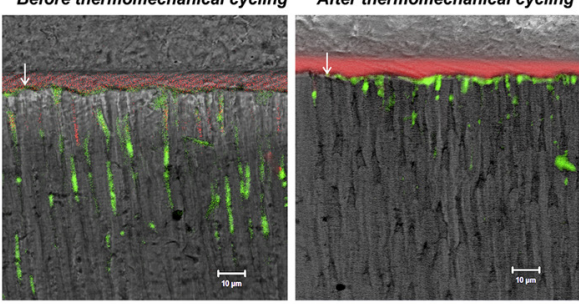

Scotchbond Universal

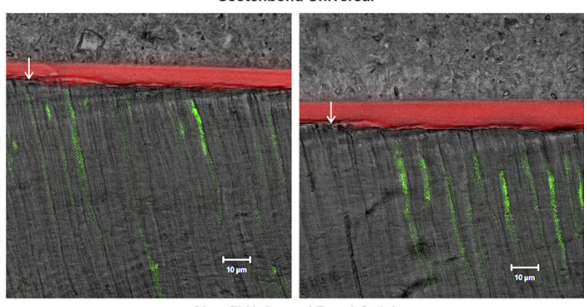

Clearfil Universal Bond Quick
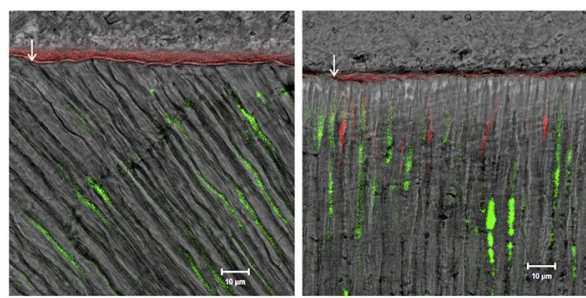

Clearfil SE Bond (control 2-step self-etch adhesive)

73.5178 .82

(6.88) (10.34)

44.0218 .80

(6.05) (5.95)

3.3125 .88

(7.26) (7.63)

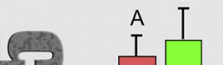

Self-etch mode
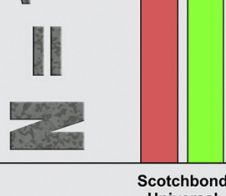

Universal

After thermomechanical cycling

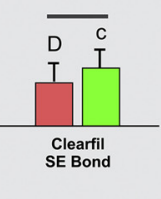

Fig. 3. In-situ zymography as an indicator of the potential degradation of resin-bonded dentin. a. Schematic of the principles of the dual-fluorescence in-situ zymography technique. b. Representative merged channels (red fluorescence for adhesive, green fluorescence for degraded fluorescein-labeled gelatin) of resin-dentin interfaces created by different adhesives used in the etch-and-rinse or self-etch mode before and after thermomechanical cycling. Bars $=10 \mu \mathrm{m}$. Open arrowheads: thicker hybrid layers created by adhesives applied in the etch-and-rinse mode. Arrows: thinner hybrid layers created by adhesives applied in the self-etch mode. c. Bar chart summarizing the percentages of areas within the hybrid layers that exhibited gelationolytic activities against the extrinsic gelatin substrate. Values are means and standard deviations. For comparisons of different adhesives/application modes, columns in the "before thermomechanical cycling" subgroups that are labeled with the same upper case letters are not significantly different ( $p>0.05$ ); columns in the "after thermomechanical cycling" subgroups that are labeled with the same lower case letters are not significantly different ( $\mathrm{p}>0.05$ ). For comparison of the combined factor "adhesive/application mode", columns connected by a black horizontal bar are not significantly different ( $p>0.05$ ). (For interpretation of the references to colour in this figure legend, the reader is referred to the web version of this article.)

formulations were: CSEB (5.73 $\pm 0.52 \%)$, CUBQ (6.34 $\pm 0.64 \%)$, SUB $(9.06 \pm 0.76 \%)$ and OSP $(10.65 \pm 0.67 \%)$. These values were significantly different $(\mathrm{p}<0.05)$, in the order (from the highest to the lowest), OSP $=$ SUB $>$ CUBQ $=$ CSEB $(p<0.05)$. For the two resins that exhibited mass loss, the maximum solubility values were SUB $(5.06 \pm 0.71 \%)$ and OSP $(3.22 \pm 0.54 \%)$; significantly more extensive leaching of resin components was observed for SUB compared with OSP ( $\mathrm{p}<0.05)$. 

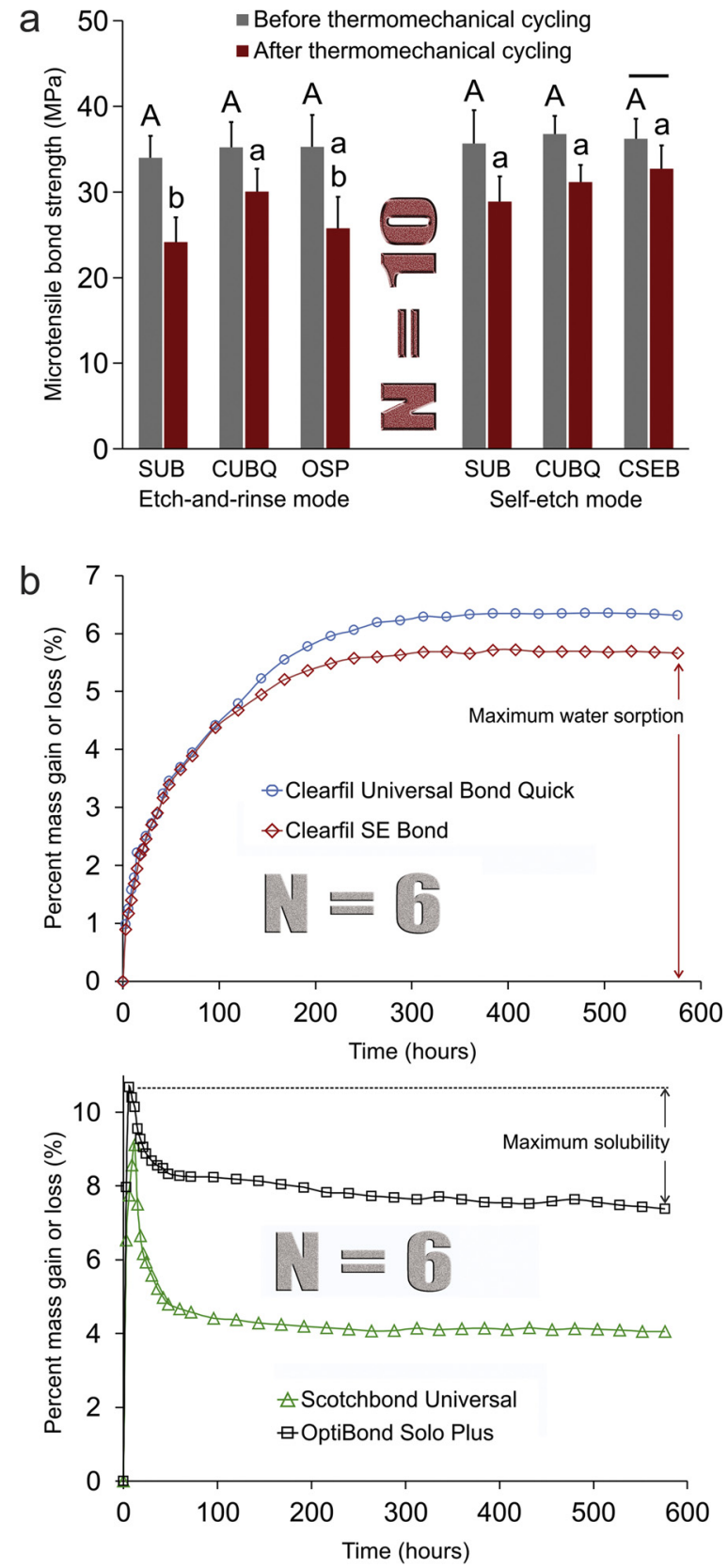

Fig. 4. Microtensile bond strengths of resin-dentin bonds and water sorption results. a. Bar chart summarizing the resin-dentin microtensile bond strengths of six "adhesive/application mode: groups before and after thermomechanical cycling. Values are means and standard deviations. Columns in the 'before thermomechanical cycling' subgroups that are labeled with the same upper case letters are not significantly different $(\mathrm{p}>0.05)$; columns in the "after thermomechanical cycling" subgroups that are labeled with the same lower case letters are not significantly different ( $p>0.05$ ). b and c. Percent mass gain/ loss of solvent-free polymerized adhesive resin formulations after immersion in water for 24 days $(576 \mathrm{~h})$. Data points represent mean values (standard deviation of each data point not shown to reduce complexity of the presentation).

\section{Discussion}

Conceptually, embodiment of a new system of things provides an emerging platform through which novel vocabularies may be utilized for addressing deficiencies that prevail in previous systems. Despite their popularity, universal adhesives have been fictitiously portrayed, in the perception of some people, as a collection of low hanging fruits [11], plucked from the trajectory of pre-existed hardwares [3] and occasionally garnished with an unsuspected decorative [29-32], to provide an epiphanic resolution that caters for versatility and universality. From a sociological perspective, we have come a long way from the Renaissance ideal of versatility [33], the Uomo Univserale, which considered that man should embrace all knowledge in his capacity as the center of the universe. Knowledge explosion beyond the Renaissance era, however, renders it increasingly impossible to accommodate this versatility injunction. The current tendency in the evolution of civilization points toward increased specialization; indeed, to be a "jack of all trades" is almost equivalent to a "master of none" in 21 st century society. In the context of dental adhesion, choosing the path of versatility likewise imposes technological sublimity on every bonding facet in which the adhesive is destined to accomplish. While most of the low hanging fruits of innovation had probably been plucked in addressing the prerequisites for bonding to different substrates, it remains to be seen whether the more treacherous task of dealing with bonding to wet dentin has been landscaped in this most recent genre of bonding solutions. Excellent treatises on universal adhesives are available in the scientific corpus; they are graciously acknowledged but will not be comprehensively listed. Few, however, have specifically been designed to identify the potential detrimental effects of moisture retention on the dentin adhesives of late [7,8,34]. Water assumes the role a double-edged sword in bonding to dentin, posing as a sanctuary or complication $[13,35,36]$. Inasmuch as the water-associated properties of adhesives define the critical barrier to progress in addressing the issue of resin-dentin bond durability [14,37], these important attributes were candidly examined using the first and the latest versions of universal adhesive systems.

Investigations were instigated based on the principles of causality [38], a metaphysical concept of progression that relates one process (the cause) with another (the effect), where the first is partly responsible for the second, and the second is partly dependent on the first [39]. A process may have many causes, which all lie in the past; an effect, in turn, may be a cause of the outcome, which resides in the future [40]. A double-fluorescence CLSM technique [41] was first used to examine interfacial permeability immediately after bonding, that being the immediate cause of bond stability. Although previous studies have utilized silver tracer to demonstrate nanoleakage, similar techniques were not employed here because of the ambiguous relevance of microleakage and nanoleakage studies [42-44]. To probe for a more time-dependent cause, water sorption of solvent-evaporated neat resins prepared from the different adhesives was used, in conjunction with thermomechanical cycling, to discriminate the potential effect of resin hydrophilicity on bond degradation [45-47]. To identify an intermediate effect, in-situ zymography was used to detect regions within the hybrid layer that were prone to future degradation [20]. It is prudent to reiterate that the technique does not generate direct evidence of collagen degradation within the hybrid layer [48]. Ultrastructural features of collagen degradation by endogenous proteases are only recognizable after long-term aging [11] and cannot be observed in simulated aging such as thermomechanical cycling [3]. The extrinsic source of quenched fluorescein-conjugated gelatin utilized in in-situ zymography simply provides an easily degradable substrate for expedited localization of areas with gelatinolytic potential. As such, this is the limitation of using in-situ zymography for examining the degradability of resindentin interfaces. Finally, microtensile bond testing was used to provide an appraisal of the eclectic consequences of the aforementioned waterassociated attributes. In all fairness, there is limited correlation between bond strength results and clinical outcomes [49,50]; comparing benchtop testing with a full-fledged clinical trial is akin to associating mass culture with high art. Exploration of antecedence and contiguity relationships is not deterministic of clinical significance. Nevertheless, bond testing before and after thermomechnical aging provides a reasonable perception of the reduction in adhesive integrity contributed by immediate and long-term water containment within the polymerized resin matrix, as well as the potential loss of natural supporting 
structural components within the partially or fully demineralized dentin.

Irrespective of the adhesive application mode, bonded dentin should be impermeable to water permeation from the pulpal side in order to achieve a fluid-tight seal. This is paramount for the longevity of bonded restorations as well as their affects their capability in resisting the development of secondary caries. Bonding to an intrinsically wet substrate curtails the use of straightly hydrophobic resinous ingredients. Incorporation of ionizable resin monomers to improve blend hydrophilicity, self-etching potential or reduce resin immiscibility after solvent evaporation indubitably leaves a history of traceable artifacts within the resin-dentin interface that accounts for immediate interfacial permeability as well as post-aging water sorption. From the present interfacial permeability records, it is apparent that the goal of achieving a fluid-tight seal has not been perfectly accomplished in all the adhesives examined. Nevertheless, lower interfacial permeability was associated with the use of the self-etching mode. Hence, the first null hypothesis that "adhesive etching mode has no consequence on the intrinsic water permeability of the resin-dentin interfaces" has to be rejected. This finding corroborated with the report that resin-dentin interfaces were more stable after 12 months when a universal adhesive was used in the self-etch mode [51]. Depending on how the smear layer is treated with different etching modes, the magnitude of interstitial pulpal pressure (i.e. uninflamed $v s$ inflamed pulps) [52], the hydrophilicity of the resinous components [47] as well as water compatibility of the photosensitizers [53], water-associated artifacts may be manifested as water-infused hybrid layers and adhesive layers [54], nanoscale phase separation into hydrophobic and hydrophilic resin-rich domains [55], water channels [56], bubbles [57] or discrete water films between the adhesive and resin composite [58]. Apart from rendering the polymerized resin matrix more susceptible to subsequent water ingress, these water-associated artifacts also increase interfacial permeability immediately after bonding [59].

In terms of water sorption, it is apparent that there are differences in mass gain or loss after the four solvent-evaporated adhesive resin comonomer blends were immersed in water for 24 days. Whereas water sorption was slower and less extensive for CSEB and CUBQ, water sorption was more extensive and took much less time to attain saturation for OSP and SUB. For the latter two adhesives, leaching of resin components was evident after the polymerized resin matrix was saturated with water [23]. Accordingly, the fourth null hypothesis that "there is no difference among the four adhesive resin blends on water sorption" has to be rejected. Because the adhesive solvents were evaporated from the resin blends prior to preparation of the resin disks, the variations in water sorption/solubility characteristics may be attributed to differences in resin composition [60] and/or the physicochemical properties of the photoinitiators [61], and are independent of the adhesive application mode. It is anticipated that when the adhesives are bonded to dentin, creation of water-associated artifacts via increases in intrinsic water permeation may further expedite the rate and extent of water ingress into the polymerized resin matrices. Irrespective of the application mode, resin-dentin interfaces created with SUB were significantly more permeable than those bonded with CUBQ. Likewise, water sorption was more extensive and rapid with the solvent-evaporated resin disks prepared from SUB. These phenomena may be attributed to the inclusion of a cocktail of hydrophilic amide resin monomers in CUBQ that permits more optimal resin infiltration and better cross-linking to create a more water-resistant polymer network during light-curing of the universal adhesive [62].

Having identified the immediate and time-dependent water-associated attributes, it is not difficult to rationalize the variations in attributes among which the adhesives and application modes should be effectuated by differences in bond stability and adhesive performance before and after thermomechanical cycling. The aging technique creates additional stresses on the bonded structures, and to a certain extent, expedites the rate of water ingress, which, in turn, hastens resin hydrolysis. Polymer swelling and leaching of resin components also account for the deterioration in mechanical properties. Indeed, the insitu zymography and microtensile bond strength results justify rejection of the third null hypothesis that "thermomechanical cycling has no effect on the gelatinolytic activity of resin-dentin interfaces created by either the etch-and-rinse or the self-etch technique", as well as the fourth null hypothesis that "there is no difference in the microtensile bond strength of the four adhesives bonded to dentin before and after thermomechanical cycling". Similar to the causes that precipitate the effects, increase in gelatinolytic activities and decline in bond strength were significantly more prominent in SUB, compared with CUBQ, even though they both contain 10-MDP and are both classified as universal adhesives.

\section{Conclusion}

Although progress is impossible without change, not all changes represent progress. The advent of universal adhesives has brought forth significant changes to the dental adhesion arena. There are now more application options, reduced bonding armamentarium and the new adhesive systems are more mesmerizing in terms of user friendliness. From a marketing perspective, these changes are important, necessary and even inevitable, to cater for consumer tastes, maintain product competitiveness or deliver workforce sustainability. Examination of the water-associated attributes of these adhesives identified, however, that the elements that are critical for making resin-dentin bonds more durable to environmental challenges and less susceptible to degradation have remained unchanged at large. Attributes such as interfacial permeability, water sorption, gelatinolytic potential and the ability to preserve mechanical strength after aging are no better, and may be even worse than the benchmarks established by former classes of adhesives.

\section{Acknowledgments}

The present study was supported by grant 2017YFC0840100 and 2017YFC0840109 from the National Key R\&D Program of China, grants 81722015 and 81720108011 from National Nature Science Foundation of China (PI: Li-na Niu, The Fourth Military Medical University), grant Processo Fapesp 2016/20437-2, Brazil (PI: Cesar Pucci, São Paulo State University UNESP), grant 2014J2200099 from Science and Technology Program of Guangzhou and grant 81200776 from National Nature Science Foundation of China (PI: Lisha Gu, Sun Yat-sen University).

\section{References}

[1] J. De Munck, K. Van Landuyt, M. Peumans, A. Poitevin, P. Lambrechts, M. Braem, B. Van Meerbeek, A critical review of the durability of adhesion to tooth tissue: methods and results, J. Dent. Res. 84 (2005) 118-132.

[2] M. Hanabusa, A. Mine, T. Kuboki, Y. Momoi, A. Van Ende, B. Van Meerbeek, J. De Munck, Bonding effectiveness of a new 'multi-mode' adhesive to enamel and dentine, J. Dent. 40 (2012) 475-484.

[3] C. Chen, L.N. Niu, H. Xie, Z.Y. Zhang, L.Q. Zhou, K. Jiao, J.H. Chen, D.H. Pashley, F.R. Tay, Bonding of universal adhesives to dentine-old wine in new bottles? J. Dent. 43 (2015) 525-536.

[4] B. Seabra, S. Arantes-Oliveira, J. Portugal, Influence of multimode universal adhesives and zirconia primer application techniques on zirconia repair, J. Prosthet. Dent. 112 (2014) 182-187.

[5] W.L. Rosa, E. Piva, A.F. Silva, Bond strength of universal adhesives: a systematic review and meta-analysis, J. Dent. 43 (2015) 765-776.

[6] T. Takamizawa, W.W. Barkmeier, K. Sai, A. Tsujimoto, A. Imai, R.L. Erickson, M.A. Latta, M. Miyazaki, Influence of different smear layers on bond durability of self-etch adhesives, Dent. Mater. 34 (2018) 246-259.

[7] I.V. Luque-Martinez, J. Perdigão, M.A. Muñoz, A. Sezinando, A. Reis, A.D. Loguercio, Effects of solvent evaporation time on immediate adhesive properties of universal adhesives to dentin, Dent. Mater. 30 (2014) 1126-1135.

[8] A.N. Choi, J.H. Lee, S.A. Son, K.H. Jung, Y.H. Kwon, J.K. Park, Effect of dentin wetness on the bond strength of universal adhesives, Materials (Basel) 10 (2017) E1224.

[9] A. Wagner, M. Wendler, A. Petschelt, R. Belli, U. Lohbauer, Bonding performance of universal adhesives in different etching modes, J. Dent. 42 (2014) 800-807.

[10] Ö. Irmak, B.C. Yaman, E.O. Orhan, F. Ozer, M.B. Blatz, Effect of rubbing force magnitude on bond strength of universal adhesives applied in self-etch mode, Dent. 
Mater. J. 37 (2018) 139-145

[11] Z.Y. Zhang, F.C. Tian, L.N. Niu, K. Ochala, C. Chen, B.P. Fu, X.Y. Wang, D.H. Pashley, F.R. Tay, Defying ageing: an expectation for dentine bonding with universal adhesives? J. Dent. 45 (2016) 43-52.

[12] P. Totaro, T.A. Marinho, The duality of social self-categorization in consumption, J. Consumer Cult. 0 (0) (2017) 1-24.

[13] F.R. Tay, R.M. Carvalho, D.H. Pashley, Water movement across bonded dentin - too much of a good thing, J. Appl. Oral Sci. 12 (2004) 12-25 (spe).

[14] M.G. Brackett, N. Li, W.W. Brackett, R.J. Sword, Y.P. Qi, L.N. Niu, C.R. Pucci, A. Dib, D.H. Pashley, F.R. Tay, The critical barrier to progress in dentine bonding with the etch-and-rinse technique, J. Dent. 39 (2011) 238-248.

[15] A. Frassetto, L. Breschi, G. Turco, G. Marchesi, R. Di Lenarda, F.R. Tay, D.H. Pashley, M. Cadenaro, Mechanisms of degradation of the hybrid layer in ad hesive dentistry and therapeutic agents to improve bond durability - a literature review, Dent. Mater. 32 (2016) e41-53.

[16] L. Breschi, T. Maravic, S.R. Cunha, A. Comba, M. Cadenaro, L. Tjäderhane, D.H. Pashley, F.R. Tay, A. Mazzoni, Dentin bonding systems: from dentin collagen structure to bond preservation and clinical applications, Dent. Mater. 34 (2018) 78-96.

[17] D.H. Pashley, F.R. Tay, C. Yiu, M. Hashimoto, L. Breschi, R.M. Carvalho, S. Ito, Collagen degradation by host-derived enzymes during aging, J. Dent. Res. 83 (2004) 216-221.

[18] Y. Kuboki, G.L. Mechanic, Comparative molecular distribution of cross-link in bone and dentin collagen. Structure-function relationships, Calcif. Tissue Int. 34 (1982) 306-308.

[19] S.J. George, J.L. Johnson, In situ zymography, Methods Mol. Biol. 622 (2010) 271-277.

[20] A. Mazzoni, F.D. Nascimento, M. Carrilho, I. Tersariol, V. Papa, L. Tjäderhane, R. Di Lenarda, F.R. Tay, D.H. Pashley, L. Breschi, MMP activity in the hybrid layer detected with in situ zymography, J. Dent. Res. 91 (2012) 467-472.

[21] L.C. Perote, M.B. Kamozaki, N.C. Gutierrez, F.R. Tay, C.R. Pucci, Effect of matrix metalloproteinase-inhibiting solutions and aging methods on dentin bond strength, J. Adhes. Dent. 17 (2015) 347-352.

[22] D.H. Pashley, R.M. Carvalho, H. Sano, M. Nakajima, M. Yoshiyama, Y. Shono, C.A. Fernandes, F. Tay, The microtensile bond test: a review, J. Adhes. Dent. 1 (1999) 299-309.

[23] C.K. Yiu, N.M. King, M.R. Carrilho, S. Sauro, F.A. Rueggeberg, C. Prati, R.M. Carvalho, D.H. Pashley, F.R. Tay, Effect of resin hydrophilicity and temperature on water sorption of dental adhesive resins, Biomaterials 27 (2006) 1695-1703.

[24] Y. Yoshida, K. Yoshihara, N. Nagaoka, S. Hayakawa, Y. Torii, T. Ogawa, A. Osaka, B.V. Meerbeek, Self-assembled nano-layering at the adhesive interface, J. Dent. Res. 91 (2012) 376-381.

[25] F. Tian, L. Zhou, Z. Zhang, L. Niu, L. Zhang, C. Chen, J. Zhou, H. Yang, X. Wang, B. Fu, C. Huang, D.H. Pashley, F.R. Tay, Paucity of nanolayering in resin-dentin interfaces of MDP-based adhesives, J. Dent. Res. 95 (2016) 380-387.

[26] A. Mazzoni, P. Scaffa, M. Carrilho, L. Tjäderhane, R. Di Lenarda, A. Polimeni, A. Tezvergil-Mutluay, F.R. Tay, D.H. Pashley, L. Breschi, Effects of etch-and-rinse and self-etch adhesives on dentin MMP-2 and MMP-9, J. Dent. Res. 92 (2013) 82-86.

[27] A.R. Hannas, J.C. Pereira, J.M. Granjeiro, L. Tjäderhane, The role of matrix metalloproteinases in the oral environment, Acta Odontol. Scand. 65 (2007) 1-13.

[28] L. Tjäderhane, M.R. Carrilho, L. Breschi, F.R. Tay, D.H. Pashley, Dentin basic structure and composition - an overview, Endod. Topics 20 (2012) 3-29.

[29] K. Yoshihara, N. Nagaoka, A. Sonoda, Y. Maruo, Y. Makita, T. Okihara, M. Irie, Y. Yoshida, B. Van Meerbeek, Effectiveness and stability of silane coupling agent incorporated in 'universal' adhesives, Dent. Mater. 32 (2016) 1218-1225.

[30] A. Elsayed, F. Younes, F. Lehmann, M. Kern, Tensile bond strength of so-called universal primers and universal multimode adhesives to zirconia and lithium disilicate ceramics, J. Adhes. Dent. 19 (2017) 221-228.

[31] A.F.V. Moro, A.B. Ramos, G.M. Rocha, C.D.R. Perez, Effect of prior silane application on the bond strength of a universal adhesive to a lithium disilicate ceramic, J. Prosthet. Dent. 118 (2017) 666-671.

[32] C. Yao, L. Zhou, H. Yang, Y. Wang, H. Sun, J. Guo, C. Huang, Effect of silane pretreatment on the immediate bonding of universal adhesives to computer-aided design/computer-aided manufacturing lithium disilicate glass ceramics, Eur. J. Oral Sci. 125 (2017) 173-180.

[33] Polymath - New World Encyclopedia, web.newworldencyclopedia.org. (Accessed 01-27-2018).

[34] A. Sezinando, I. Luque-Martinez, M.A. Muñoz, A. Reis, A.D. Loguercio, J. Perdigão, Influence of a hydrophobic resin coating on the immediate and 6-month dentin bonding of three universal adhesives, Dent. Mater. 31 (2015) e236-246.

[35] F.R. Tay, D.H. Pashley, R.R. Kapur, M.R. Carrilho, Y.B. Hur, L.V. Garrett, K.C. Tay, Bonding BisGMA to dentin - a proof of concept for hydrophobic dentin bonding, J. Dent. Res. 86 (2007) 1034-1039.

[36] S. Mai, C.C. Wei, L.S. Gu, F.C. Tian, D.D. Arola, J.H. Chen, Y. Jiao, D.H. Pashley,
L.N. Niu, F.R. Tay, Extrafibrillar collagen demineralization-based chelate-and-rinse technique bridges the gap between wet and dry dentin bonding, Acta. Biomater. 57 (2017) 435-448.

[37] P. Spencer, Q.Y. Jonggu Park, A. Misra, B.S. Bohaty, V. Singh, R. Parthasarathy, F. Sene, S.E. de Paiva Gonçalves, J. Laurence, Durable bonds at the adhesive/dentin interface: an impossible mission or simply a moving target? Braz Dent. Sci. 15 (2012) 4-18.

[38] D. Hume, D.F. Norton, M.J. Norton (Eds.), A Treatise of Human Nature, Clarendon Press, Oxford, United Kingdom, 2007.

[39] The action of causing; the relation of cause and effect. Oxford English Dictionary Online, January 2018, Oxford University Press, Oxford, United Kingdom (Accessed 1-28-2018).

[40] D. Lewis, Causation, J. Philos. 70 (1973) 556-567.

[41] N. Sartori, L.D. Peruchi, J.H. Phark, M.M. Lopes, É. Araújo, L.C. Vieira, R. Belli, S. Duarte Jr, Permeation of intrinsic water into ethanol- and water-saturated, monomer-infiltrated dentin bond interfaces, Dent. Mater. 31 (2015) 1385-1395.

[42] F.R. Tay, N.M. King, K.M. Chan, D.H. Pashley, How can nanoleakage occur in selfetching adhesive systems that demineralize and infiltrate simultaneously? J. Adhes. Dent. 4 (2002) 255-269.

[43] S.D. Heintze, Systematic reviews: i. The correlation between laboratory tests on marginal quality and bond strength. II. The correlation between marginal quality and clinical outcome, J. Adhes. Dent. 9 (Suppl. 1) (2007) 77-106.

[44] E. Hasanli, The relevance of micro-leakage and nanoleakage studies, 12th International Congress of Iranian Academy of Restorative Dentistry, 24-26 October 2012, Tabriz-Iran, 2012 (Abstr. 4280).

[45] N.M. King, N. Hiraishi, C.K. Yiu, E.L. Pashley, R.J. Loushine, F.A. Rueggeberg, D.H. Pashley, F.R. Tay, Effect of resin hydrophilicity on water-vapour permeability of dental adhesive films, Eur. J. Oral Sci. 113 (2005) 436-442.

[46] Y. Nishitani, M. Yoshiyama, K. Hosaka, J. Tagami, A. Donnelly, M. Carrilho, F.R. Tay, D.H. Pashley, Use of Hoy's solubility parameters to predict water sorption/ solubility of experimental primers and adhesives, Eur. J. Oral Sci. 115 (2007) $81-86$

[47] M. Cadenaro, L. Breschi, F.A. Rueggeberg, K. Agee, R. Di Lenarda, M. Carrilho, F.R. Tay, D.H. Pashley, Effect of adhesive hydrophilicity and curing time on the permeability of resins bonded to water vs. ethanol-saturated acid-etched dentin, Dent. Mater. 25 (2009) 39-47.

[48] M.R. Carrilho, S. Geraldeli, F. Tay, M.F. de Goes, R.M. Carvalho, L. Tjäderhane, A.F. Reis, J. Hebling, A. Mazzoni, L. Breschi, D. Pashley, In vivo preservation of the hybrid layer by chlorhexidine, J. Dent. Res. 86 (2007) 529-533.

[49] B. Van Meerbeek, M. Peumans, A. Poitevin, A. Mine, A. Van Ende, A. Neves, J. De Munck, Relationship between bond-strength tests and clinical outcomes, Dent. Mater. 26 (2010) e100-121.

[50] S.D. Heintze, C. Thunpithayakul, S.R. Armstrong, V. Rousson, Correlation between microtensile bond strength data and clinical outcome of Class V restorations, Dent Mater. 27 (2011) 114-125.

[51] G. Marchesi, A. Frassetto, A. Mazzoni, F. Apolonio, M. Diolosà, M. Cadenaro, R. Di Lenarda, D.H. Pashley, F. Tay, L. Breschi, Adhesive performance of a multi-mode adhesive system: 1-year in vitro study, J. Dent. 42 (2014) 603-612.

[52] K.J. Heyeraas, E. Berggreen, Interstitial fluid pressure in normal and inflamed pulp, Crit. Rev. Oral Biol. Med. 10 (1999) 328-336.

[53] F. Abedin, B. Roughton, Q. Ye, P. Spencer, K. Camarda, Computer-aided molecular design of watercompatible visible light photosensitizers for dental adhesive, Chem. Eng. Sci. 159 (2017) 131-139.

[54] F.R. Tay, D.H. Pashley, B.I. Suh, R.M. Carvalho, A. Itthagarun, Single-step adhesives are permeable membranes, J.Dent 30 (2002) 371-382.

[55] Q. Ye, Y. Wang, P. Spencer, Nanophase separation of polymers exposed to simulated bonding conditions, J. Biomed. Mater. Res. B. Appl. Biomater. 88 (2009) 339-348.

[56] F.R. Tay, D.H. Pashley, M. Yoshiyama, Two modes of nanoleakage expression in single-step adhesives, J. Dent. Res. 81 (2002) 472-476.

[57] F.R. Tay, D.H. Pashley, B.I. Suh, N. Hiraishi, C.K. Yiu, Water treeing in simplified dentin adhesives-déjà vu? Oper. Dent. 30 (2005) 561-579.

[58] F.R. Tay, D.H. Pashley, N. Hiraishi, S. Imazato, F.A. Rueggeberg, U. Salz, J. Zimmermann, N.M. King, Tubular occlusion prevents water-treeing and throughand-through fluid movement in a single-bottle, one-step self-etch adhesive model, J. Dent. Res. 84 (2005) 891-896.

[59] M. Hashimoto, S. Ito, F.R. Tay, N.R. Svizero, H. Sano, M. Kaga, D.H. Pashley, Fluid movement across the resin-dentin interface during and after bonding, J. Dent. Res. 83 (2004) 843-848.

[60] J. Malacarne, R.M. Carvalho, M.F. de Goes, N. Svizero, D.H. Pashley, F.R. Tay, C.K. Yiu, M.R. Carvalho, Water sorption/solubility of dental adhesive resins, Dent. Mater. 22 (2006) 973-980.

[61] X. Guo, Y. Wang, P. Spencer, Q. Ye, X. Yao, Effects of water content and initiator composition on photopolymerization of a model BisGMA/HEMA resin, Dent. Mater. 24 (2008) 824-831.

[62] P. Schouten, Super stick, super quick!, Brit. Dent. J. 222 (2017) 904. 